\title{
PENGARUH KEPEMIMPINAN TRANSFORMASIONAL TERHADAP KINERJA KARYAWAN YANG DIMEDIASI OLEH MOTIVASI
}

\author{
Michael Veliando dan Yanuar \\ ${ }^{1}$ Program Studi Manajemen, Fakultas Ekonomi Universitas Tarumanagara, Jakarta \\ Email : Michael.115160086@stu.untar.ac.id
}

\begin{abstract}
The purpose of research is to obtain empirical evidence about the effect of transformational leadership on employee performance mediated by motivation. This study used $C V$. Prima Ujaya Snack's employees as sample population using purposive sampling method. The size of sample are 65 samples using SEM. Questionnaire data obtained from employees and supervisor. The data used are primary data in the form of a questionnaire. This research uses Microsoft Office 365 software, SmartPLS version 3.3.2 to perform data processing. The results obtained in this research are transformational leadership had a positive and significant relation with employee performance. Transformational leadership had a appositive and significant relation with motivation. And motivation indeed mediated transformational leadership on employee performance.
\end{abstract}

Keywords: Transformational Leadership, Motivation, Employee Performance.

\begin{abstract}
ABSTRAK: Tujuan penelitian ini adalah untuk memperoleh bukti empiris mengenai pengaruh kepemimpinan transformasional terhadap kinerja karyawan dengan motivasi sebagai variabel mediasi. Penelitian ini menggunakan populasi karyawan CV. Prima Ujaya Snack dengan metode purposive sampling. Ukuran sampel sebanyak 65 sampel menggunakan metode SEM. Data yang digunakan adalah data primer berupa kuesioner yang dibagikan kepada karyawan dan supervisor. Penelitian ini menggunakan software Microsoft Office 365, dan SmartPLS versi 3.3.2 untuk melakukan pengolahan data. Hasil yang diperoleh dalam penelitian ini yaitu kepemimpinan transformasional memliki pengaruh positif dan signifikan terhadap kinerja karyawan. Kepemimpinan transformasional memiliki pengaruh yang positif dan signifikan terhadap motivasi. Dan motivasi memilliki hubungan yang positif dan signifikan terhadap kinerja karyawan dan dapat memediasi antara kepemimpinan transformasional dengan kinerja karyawan.
\end{abstract}

Kata kunci: Kepemimpinan Transformasional, Motivasi, Kinerja Karyawan.

\section{LATAR BELAKANG}

Studi mengenai sumber daya manusia sangat menarik untuk dibahas dalam dekade ini, terutama dalam era globalisasi sekarang ini, Organisasi atau perusahaan harus mampu mengelola manajemen didalam perusahaan untuk tumbuh dan berkembang dengan tujuan yang ingin dicapai 
perusahaan. Organisasi diharapkan untuk mempertahankan kinerjanya di perusahaan (Rao \& Abdul (2015)). Seperti dilihat dari karya oleh para peneliti sumber daya manusia (Bacha, Eliane (2013)) yang membahas tentang kepemimpinan transformasional tentang peranan, dan proses yang dilakukan untuk meningkatkan kinerja.

Kepemimpinan transformasional merupakan faktor penting dalam keberhasilan kepemimpinan dan menjadi faktor penting sebagai penentu keberhasilan usaha para pengikutnya (Bass 2011). Untuk meningkatkan kinerja yang optimal, kepemimpinan yang optimal bagi para bawahan juga harus diterapkan. Banyak factor yang menjadi penentu mengapa harus meningkatkan kinerja didalam perusahaan (Charbonneau,Kelloway \& Barling (2017)).

Sekalipun banyak factor yang mempengaruhi kinerja, namun dalam studi (Balansa, Lengkong \& Hasam (2017)) menemukan bahwa kepemimpinan transformasional tidak memberikan pengaruh untuk meningkatkan kinerja karyawan. Oleh karna itu muncul pertanyaan Sekalipun banyak factor yang mempengaruhi kinerja. Menangani research gap tersebut, studi ini mengadopsi variable mediasi motivasi (Wen Lee \& Hidayat, 2018) menjelaskan teori Transformational Leadership akan lebih berdampak terhadap kinerja dengan adanya mediasi motivasi. Logika adalah bahwa Transformational Leadership dengan adanya dorongan motivasi akan membuat kinerja menjadi optimal.

Studi ini dilakukan di perusahaan yang memproduksi makanan ringan CV. Prima Ujaya Snack di Jambi. CV. Prima Ujaya Snack memiliki berbagai macam departemen pekerjaan yang dibagi dalam setiap organisasi, antara lain : Departemen Kantor, Departemen Marketing, Departemen Packing, Departemen Produksi. Dari berbagai departemen tersebut masih banyak terdapat permasalahan kinerja yang dilakukan oleh para karyawan di perusahaan, seperti tidak tepat waktu dalam bekerja, tidak mengikuti peraturan yang berlaku diperusahaan.

Berdasarkan uraian di atas, maka ditentukan rumusan masalah dalam penelitian ini adalah ingin menguji apakah terdapat hubungan positif kepemimpinan transformasional terhadap kinerja karyawan di CV. Prima Ujaya Snack Jambi dan juga pengujian peran motivasi sebagai mediator.

\section{KAJIAN TEORI}

\section{Kepemimpinan Transformasional}

Kepemimpinan transformasional merupakan faktor penting bagi pemimpin dalam membina organisasi. Kepemimpinan transformasional juga dibutuhkan agar menginspirasi organisasi untuk meningkatkan motivasi dan inovasi. Adapun pengertian kepemimpinan transformasional Menurut Bass (1998), yaitu kepemimpinan yang dapat membuat para pengikutnya memiliki rasa kagum, percaya, loyal ke pemimpin tersebut. Yang menunjukan bahwa pemimpin dengan jiwa seperti yang dijelaskan adalah pemimpin yang diharapkan dapat membawa perubahan di perusahaan dan membawa perubahan ke pengikutnya. Selain itu, diharapkan juga dapat mendapatkan kepercayaan dan menjadi pendorong bagi pengikutnya. Sedangkan menurut Robbins dan Judge (2008), pemimpin transformasional merupakan pemimpin yang dapat menginspirasi para pengikutnya untuk mengesampingkan kepentingan pribadi demi kebaikan di organisasi dan mampu memiliki pengaruh yang luar biasa pada diri para pengikutnya. Sehingga jiwa kepemimpinan seperti dari penjelasan tersebut merupakan kepemimpinan yang dipercaya dapat membawa perubahan bersama 
dalam mencapai tujuan bersama didalam organisasi. Ada beberapa karakteristik dalam kepemimpinan transformasional Menurut N.M Tichy dan M.A (1986) Devanna, yaitu : menjadi agent of change, courageous, trust, mempunyai a strong self of values, dapat belajar dari kesalahan orang lain maupun kesalahan sendiri, dapat mengatasi masalah yang kompleks, dan Visionary. Selain karakteristik, ada juga dimensi-dimensi dari kepemimpinan transformasional menurut Yukl (2010) yaitu : Karismatik, Inspirasional, dapat memberikan stimulus intelektual dan dapat memperhatikan kebutuhan individu.

\section{Motivasi}

Motivasi merupakan arti lain dari dorongan untuk melakukan sesuatu. Motivasi merupakan pendorong bagi individu maupun organisasi agar terpacu dalam melakukan sesuatu karena ada target atau tujuan yang ingin dicapai. Menurut Robert L. Mathis dan John H. Jackson (2006), motivasi merupakan suatu keinginan yang ada didalam individu sebagai penyebab orang tersebut melakukan sesuatu. Sedangkan motivasi menurut Stephen P. Robbins dan Timothy A. Judge (2008) suatu proses yang menjelaskan intensitas, arah dan ketekunan usaha untuk mencapai suatu tujuan. Didalam motivasi terdapat beberapa dimensi yang disimpulkan oleh Abraham Maslow (1943-1970) yaitu : Physiological-need, Safety-need, Social-need, Esteem-need, dan Selfactualization-need.

\section{Kinerja Karyawan}

Kinerja adalah faktor dominan didalam perusahaan. Menurut Gibson (1988:179) kinerja adalah hasil yang dicapai dari perilaku anggota organisasi. Hasil yang diinginkan organisasi dari perilaku orang-orang yang ada di dalamnya disebut sebagai kinerja . Simanjuntak (2005) berpendapat bahwa kinerja adalah tingkat pencapaian hasilatas pelaksanaan tugas-tugas tertentu. sedangkan menurut Simamora (2006) kinerja merupakan suatu proses untuk melakukan evaluasi dalam pelaksanaan hasil individu maupun kelompok yang dipakai organisasi. Ada faktor-faktor yang menjadi penanda keberhasilan kinerja menurut Robbins (2016 :263) : kualitas kerja, kuantitas kerja, ketepatan waktu, efektivitas, kemandirian, dan komitmen. Dari enam faktor tersebut merupakan faktor penting penunjang keberhasilan kinerja didalam perusahaan. Dengan terpenuhinya faktor-faktor tersebut, tentu dapat mengoptimalkan kinerja.

\section{Kaitan antar Variabel}

Telah banyak penelitian yang menunjukan adanya pengaruh antara variabel kepemimpinan transformasional terhadap kinerja. Antara lain Jyoti dan Bhau (2015) menyatakan bahwa dengan karakteristik kepemimpinan transformasional yang influence dapat memberikan pengaruh yang positif terhadap kinerja dengan positif. Lalu, dalam penelitian Elgelal dan Noermijati (2014) berpendapat jika terdapat motif kepemimpinan inspirasional didalam kepemimpinan yang dilakukan, maka pengaruh kepemimpinan dapat meningkatkan kinerja karyawan. Selanjutnya, dalam penelitian Boerner, Eisenbeiss, dan Griesser (2007) menemukan bahwa kepemimpinan transformasional sangatlah berdampak terhadap kinerja karyawan dengan adanya OCB yang terjadi karena pengaruh kepemimpinan transformasional tersebut untuk mendapatkan hasil yang Extraordinary.

H1 : Ada hubungan positif dan signifikan antara Kepemimpinan Transformasional dengan Kinerja Karyawan 
Dalam Penelitian Laid, Mohammed \& Bindu (2020) menyatakan bahwa Kepemimpinan transformasional yang dilakukan dengan membangun rasa percaya dan menunjukan rasa empati dengan adanya keterkaitan motivasi yang meliputi motivasi internal maupun eksternal memberikan hasil yang positif. Zhang, Chen, Lyu dan Shu (2020) menemukan bahwa kepemimpinan transformasional sangatlah berdampak terhadap karyawan dan memiliki hubungan yang kuat dengan adanya motivasi instrinsik didalamnya. Roy Johan, Wayan Gede, dan I Gede Riana (2014) berpendapat Kepemimpinan Transformasional memiliki hubungan positif ke Motivasi. Berdasarkan hasil analisis yang didapat dari penelitian tersebut, menyatakan bahwa semakin kuat kepemimipinan transformasional maka semakin kuat motivasinya.

\section{H2 : Ada hubungan positif dan signifikan antara Kepemimpinan Transformasional terhadap Motivasi}

Dalam Penelitian Yanuar (2017) menyatakan tidak ada hubungan yang signifikan antara motivasi karyawan dengan kinerja. Meningkatnya kompensasi meningkatkan motivasi tetapi tidak mengimprove kinerja karyawan. Motivasi dapat memediasi, tetapi tidak memberikan timbal balik yang positif. Ghaffari, Nazri dan Burgoyne (2017) menyatakan ada pengaruh positif Motivation (motivasi) terhadap Job Performance (kinerja). Menemukan bahwa dengan adanya kepuasan dari karyawan seperti kepuasan gaji dan benefits menjadi factor dari motivasi sehingga meningkatkan kinerja karyawan. Yeti Kuswati (2020) menyatakan bahwa motivasi memberikan pengaruh dan dampak yang positif sebagai support untuk meningkatkan kinerja dan mempengaruhi kelompok untuk membentuk kepemimpinan pemimpinnya.

\section{H3 : Ada hubungan positif dan signifikan antara Motivasi terhadap Kinerja Karyawan}

Berdasarkan uraian diatas, dengan demikian, model penelitian dapat dilihat pada ilustrasi gambar 1 berikut :

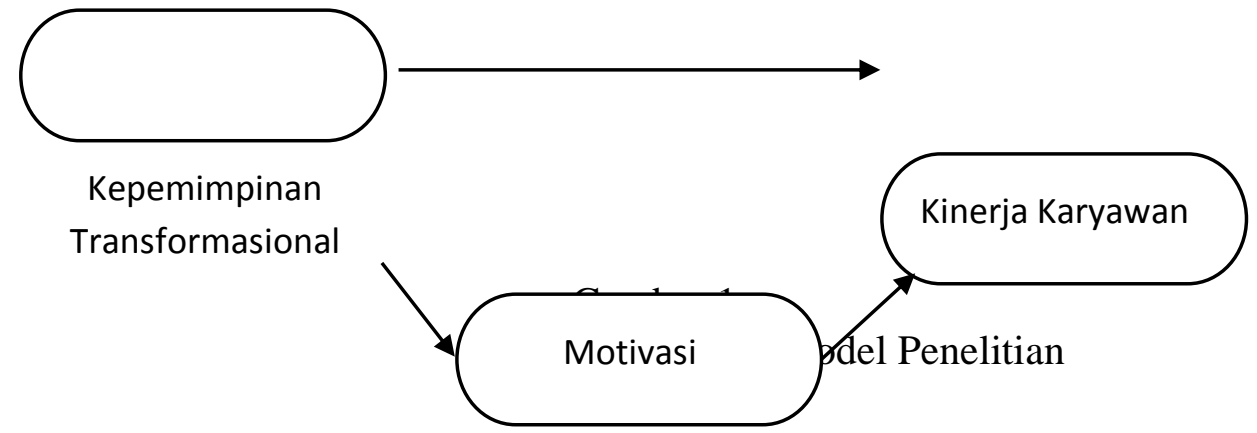

\section{METODOLOGI}

Dalam penelitian ini, menggunakan pendeketan kuantitatif (Sugiyono (2013)). Penelitian ini dilakukan dengan cara membagikan kuesioner kepada para responden yang telah sesuai dengan kriteria yang telah ditetapkan penulis. Desain penelitian yang digunakan adalah desain 
deskriptif kausalitas (Sugiyono (2007: 30)). Variabel yang ada dalam penelitian ini yaitu variabel X, Y, M. Variabel X adalah kepemimpinan transformasional, Variabel Y adalah Kinerja Karyawan, dan Variabel $\mathrm{M}$ adalah Motivasi.

Populasi yang digunakan adalah karyawan CV. Prima Ujaya Snack Jambi. Teknik pemilihan sampel pada penelitian ini adalah Purposive Sampling (Sugiyono(2014:126)). Penentuan ukuran sampel menggunakan metode SEM, pada pengukuran sampel ini mengikuti pedoman penentuan dasar menurut Hair et al. (2014). penelitian ini menggunakan 65 sampel subjek penelitian yang memiliki karakteristik yang ditentukan penulis yaitu, Jenis kelamin dengan mayoritas 37 sampel (57\%) merupakan pria dan 28 sampel (43\%) merupakan perempuan. Usia dengan mayoritas sebanyak 49 sampel $(75 \%)$ berusia $>21$ Tahun. sebanyak 16 sampel $(25 \%)$ berusia <21 Tahun. Departemen dengan mayoritas sebanyak 25 sampel (38\%) berada di departemen packing, lainnya sebanyak 15 sampel (23\%) berada di departemen kantor, sebanyak 5 sampel (8\%) berada di departemen marketing, sebanyak 20 sampel (31\%) berada di departemen produksi.

Penelitian ini menggunakan SmartPLS 3.3.2. Model spesifikasi PLS dievaluasi dengan melalui dua tahap yaitu evaluasi Outer Model (Model pengukuran validitas dan reliabilitas) dan Inner model (Struktural).

\section{Pengukuran}

Alat pengumpulan data yang digunakan adalah kuesioner yang terdiri dari tiga jenis variabel dengan masing-masing indikator. Dalam satu kuesioner tersebut terdiri dari alat ukur Kepemimpinan Transformasional, Motivasi, dan Kinerja Karyawan. Alat ukur kepemimpinan transformasional milik Bass (1998) memiliki 4 dimensi Charismatic, Inspirational, Stimulus Intelectual, Individu cinsideration dengan rentang skala 1-5 dari sangat tidak setuju - sangat setuju. Variabel kepemimpinan transformasional memiliki empat butir pernyataan. Contoh butir dengan hasil nilai tertinggi dari kepemimpinan transformasional adalah: "Pimpinan di perusahaan memberikan kepemimpinan yang inspiratif bagi karyawan" Melalui hasil uji reliabilitas, diketahui bahwa alat ukur kepemimpinan transformasional tergolong reliabel $(\alpha=0.774)$. Hal ini juga diuji untuk alat ukur motivasi milik Deci and Ryan (2008) dengan skala 1-5 dari sangat tidak setuju sampai dengan sangat setuju. Alat ukur ini terdiri dari empat butir pernyataan, dengan contoh butir dengan hasil nilai tertinggi dari pernyataannya adalah: "Saya merasa terinspirasi untuk berkembang didalam perusahaan ini.". Melalui hasil uji reliabilitas, diketahui bahwa alat ukur motivasi tergolong reliabel $(\alpha=0.881)$. Alat ukur kinerja karyawan milik Jyoti \& Bhau (2015). Dengan 1-5 dari sangat tidak setuju sampai dengan sangat setuju. Terdiri dari lima butir pernyataan yang dibagikan kepada supervisor. Kinerja yang dimaksud merupakan kinerja karyawan perusahaan, maka harus diukur dan diberi penilaian oleh atasan (supervisor). Contoh butir pernyataannya dengan hasil nilai tertinggi dari variabel kinerja karyawan adalah: "karyawan bekerja sesuai dengan peraturan yang ada didalam perusahaan

." Melalui hasil uji reliabilitas, diketahui bahwa alat ukur kinerja karyawan tergolong reliabel $(\alpha=0.859)$.

\section{HASIL DAN PEMBAHASAN}

\section{Pengujian Outer Model Validitas}

Validitas merupakan standar dari suatu variabel dapat diterima atau tidak. Uji ini dilakukan untuk mengetahui apakah konstruk yang digunakan dalam penelitian ini valid atau tidak. Uji 
validitas dilakukan melalui 3 jenis pengujian yaitu convergent validity, discriminant validity, dan average variance extracted (AVE).

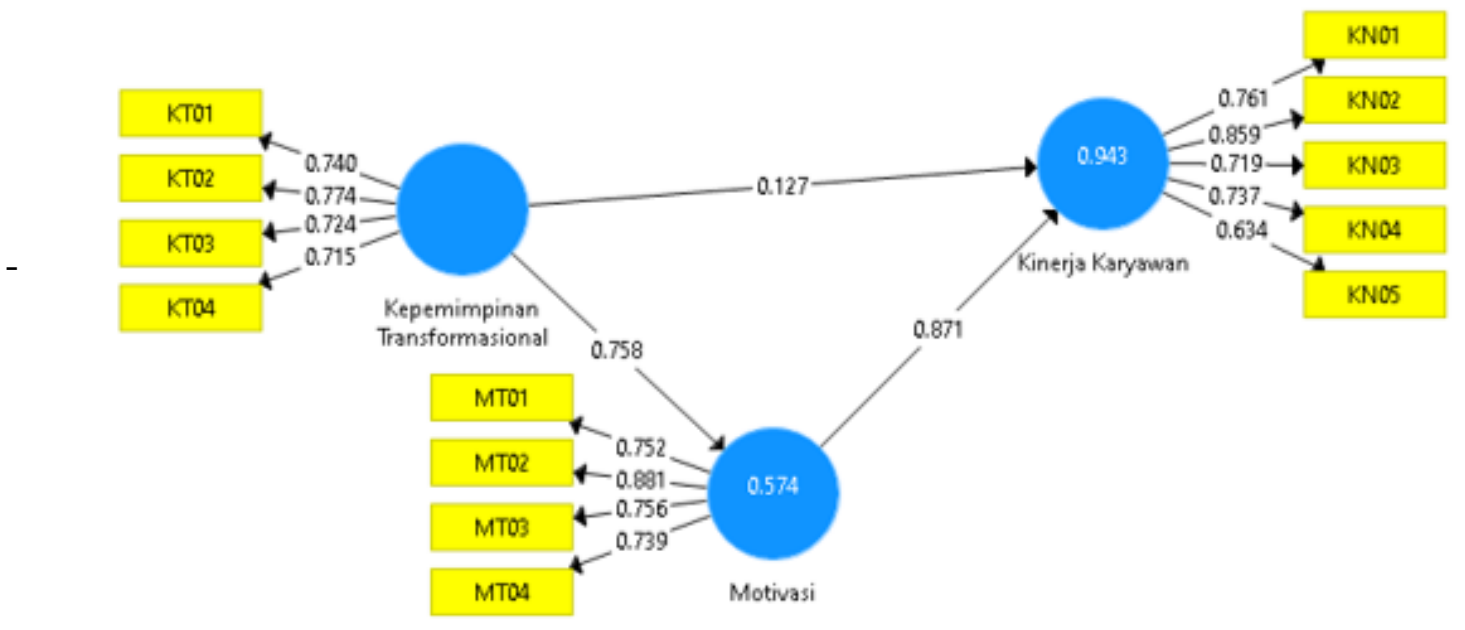

Gambar 2

Hasil Outer Loading

Suatu indikator dapat dinyatakan valid apabila nilai outer loading-nya diatas 0,7 dengan nilai minimum 0,5, jika dibawah 0,5 maka konstruk harus di hilangkan Ghozali (2006). Seluruh konstruk dari penelitian ini sudah diatas 0,5 , maka lolos uji convergent validity. Discriminant validity, nilai validitas diskriminan dapat dinilai dengan cross loading pengukuran dengan konstruknya Ghozali (2015:77). Average variance extracted (AVE) digunakan untuk menilai validitas konvergen dari masing-masing konstruk (Ansong, 2017). Nilai AVE dikatakan valid jika >0,5. Dari hasil penelitian ini yaitu : Kepemimpinan transformasional memiliki nilai AVE 0,545, motivasi 0,615, kinerja organisasi 0,556. Maka seluruh konstruk lolos uji AVE.

Tabel 1

Discriminant Validity dan Cross Loading

\begin{tabular}{c|ccc} 
INDIKATOR & $\begin{array}{c}\text { Kepemimpinan } \\
\text { Transformasional }\end{array}$ & Motivasi & $\begin{array}{c}\text { Kinerja } \\
\text { Karyawan }\end{array}$ \\
\hline KT01 & $\mathbf{0 . 7 4 0}$ & 0.505 & 0.520 \\
KT02 & $\mathbf{0 . 7 7 4}$ & 0.587 & 0.719 \\
KT03 & $\mathbf{0 . 7 2 4}$ & 0.521 & 0.516 \\
KT04 & $\mathbf{0 . 7 1 5}$ & 0.615 & 0.541 \\
MT01 & 0.553 & $\mathbf{0 . 7 5 2}$ & 0.740 \\
MT02 & 0.597 & $\mathbf{0 . 8 8 1}$ & 0.859 \\
MT03 & 0.752 & $\mathbf{0 . 7 5 6}$ & 0.675 \\
MT04 & 0.443 & $\mathbf{0 . 7 3 9}$ & 0.737 \\
KN01 & 0.553 & 0.752 & $\mathbf{0 . 7 6 1}$ \\
KN02 & 0.597 & 0.770 & $\mathbf{0 . 8 5 9}$
\end{tabular}




\begin{tabular}{l|lll} 
KN03 & 0.719 & 0.587 & $\mathbf{0 . 7 1 9}$ \\
KN04 & 0.433 & 0.737 & $\mathbf{0 . 7 3 9}$ \\
KN05 & 0.626 & 0.603 & $\mathbf{0 . 6 3 4}$
\end{tabular}

Nilai cross loading untuk setiap indikator dari masing-masing variabel laten lebih besar dibanding nilai cross loading jika dihubungkan dengan variabel laten lainnya Hal ini berarti bahwa setiap variabel laten sudah memiliki discriminant validity yang baik dimana beberapa variabel laten memiliki pengukur yang berkorelasi tinggi dengan konstruk lainnya.

\section{Pengujian Outer Model Reliabilitas}

Kriteria Composite Reliability harus diatas $>0,7$, jika memilikinilai diatas 0,7 maka reliabilitas tinggi. Nilai composite reliability untuk kepemimpinan transformasional 0,827 , untuk motivasi 0,864 , dan untuk kinerja karyawan 0,861. Semua konstruk memiliki nilai $>0,7$. Maka telah lolos uji. Nilai hasil cronbach's alpha diatas 0,6 maka diartikan lolos uji. Hasil untuk kepemimpinan transformasional 0,723, motivasi 0.789 , dan kinerja karyawan 0,797. Hasil dari semua konstruk diatas 0,6 dan hasil konstruk merupakan konstruk yang reliabilitas.

\section{Pengujian Inner Model}

Nilai R-Square yang dihasilkan dari uji Bootstrapping sebesar 0,941, memiliki arti bahwa besarnya pengaruh variabel $\mathrm{X}$ dan $\mathrm{M}$ terhadap $\mathrm{Y}$ adalah sebesar 94,1\% yang memiliki pengaruh yang kuat. Dan nilai dari Q-Square dengan uji Blindfolding memliki hasil sebesar 0,502 dengan arti konstruk memiliki predictive relevance dengan nilai sedang. Dan untuk hasil ujo GoF memiliki hasil sebesar 0,734 yang berarti hasil sudah lebih besar dari 0,38 yang dapat disimpulkan bahwa tingkat kesesuaian dalam penelitian ini sangat kuat.

Tabel 2

Hasil Uji Hipotesis

\begin{tabular}{|c|c|c|c|}
\hline INDIKATOR & $\begin{array}{c}\text { Original } \\
\text { Sample }\end{array}$ & T-Statistics & P-Values \\
\hline $\begin{array}{c}\text { Kepemimpinan Transformasional } \\
\text { > Kinerja Karyawan }\end{array}$ & 0.127 & 2.915 & 0.004 \\
\hline $\begin{array}{c}\text { Kepemimpinan Transformasional } \\
\text { > Motivasi }\end{array}$ & 0.758 & 12.165 & 0.000 \\
\hline Motivasi > Kinerja Karyawan & 0.871 & 22.539 & 0.000 \\
\hline
\end{tabular}

\section{DISKUSI}

Hipotesis pertama menyatakan Kepemimpinan Transformasional memiliki pengaruh yang positif terhadap Kinerja Karyawan di CV. Prima Ujaya Snack. Semakin kuat kepemimpinan transformasional maka semakin meningkatnya kinerja karyawan diperusahaan. Hasil ini sesuai dengan penelitian yang dilakukan oleh Jyoti dan Bhau (2015) yang menyatakan bahwa kepemimpinan transformasional memberikan pengaruh yang positif terhadap kinerja dengan signifikan, dan sesuai dengan hasil penelitian yang dilakukan oleh elgegal dan noermijati 
(2014) yang menyatakan kepemimpinan transformasional yang inspiratif akan memberikan pengaruh terhadap kinerja karyawan. Maka dapat disimpulkan bahwa H1 diterima.

Hipotesis kedua menyatakan kepemimpinan transformasional memiliki pengaruh yang positif terhadap Motivasi. Logikanya adalah semakin kuat kepemimpinan transformasional yang diberikan, maka semakin kuat motivasi pada karyawan. Dengan adanya motivasi sebagai pendorong yang lebih maka kepemimpinan transformasional akan lebih dapat meningkatkan kemauan atau mendorong karyawan untuk melaksanakan dan menyelesaikan tujuan yang ingin dicapai. Hasil ini sesuai dengan penelitian Laid, Mohammed, dan Bindu (2020), dan sesuai dengan hasil penelitian oleh Zhang, Chen, Lee, dan Shu (2020) yang menyatakan kepemimpinan transformasional memiliki hubungan yang positif dengan adanya support dari motivasi. Maka disimpulkan bahwa hipotesis kedua dapat diterima.

Dalam hipotesis ketiga motivasi memiliki pengaruh yang positif dan signifikan terhadap kinerja karyawan Dapat disimpulkan bahwa H3 diterima. Hasil ini sesuai dengan penelitian yang dilakukan oleh Ghaffari, Nazri, dan Burgoyne (2017) yang menyatakan bahwa motivasi memberikan pengaruh yang positif dengan adanya bantuan faktor lain didalamnya seperti dengan adanya kepuasan bekerja didalam perusahaan. Lalu hasil penelitian ini juga sesuai dengan penelitian yang dilakukan oleh Yeti Kuswati (2020) menemukan bahwa motivasi memberikan pengaruh yang signifikan karena motivasi merupakan support untuk meningkatkan kinerja karyawan. Tetapi berbeda dengan penelitian yang dilakukan oleh Yanuar (2017) yang menyatakan motivasi tidak memberikan timbal balik yang positif terhadap kinerja. Tetapi motivasi dapat bersifat memediasi antara variabel. Maka dapat disimpulkan bahwa hipotesis ketiga dapat diterima.

\section{PENUTUP}

Hasil penelitian menunjukkan bahwa kepemimpinan transformasional memiliki hubungan positif dan signifikan dengan kinerja karyawan di CV. Prima Ujaya Snack Jambi. Dengan meningkatnya kepemimpinan transformasional dalam sebuah perusahaan maka dapat meningkatkan kinerja karyawan. Selanjutnya kepemimpinan transformasional dapat mempengaruhi kinerja karyawan melalui peran motivasi sebagai mediasi. motivasi memediasi hubungan antara kepemimpinan transformasional dengan kinerja karyawan menunjukkan bahwa motivasi bukan merupakan faktor penentu dalam hubungan antara kepemimpinan transformasional dengan kinerja karyawan. Keterbatasan dalam penelitian ini adalah variabel yang digunakan hanyalah tiga variabel, saran untuk peneliti selanjutnya untuk menggunakan variabel lain yang memiliki hubungan terhadap kinerja organisasi seperti kompensasi, lingkungan kerja, dan lainnya. Dan keterbatasan lainnya penelitian ini hanya menggunakan sebanyak 65 sampel maka disarankan untuk penelitian selanjutnya untuk menambah populasi industry dengan memperluas jangkauan penelitian.

\section{DAFTAR PUSTAKA}

A.H Maslow. (1943). A Theory of Human Motivation, Psychological Review, hal. 370; A.H Maslow, Motivation and Personality (New York; Harrper and Row,1954).

Bacha, Eliane (2013). The relationship between transformational leadership, task performance and job characteristics. Journal of Management Development. Vol. 33 No. 4 pp. 410420. Emerald. 
Balansa.,Lengkong. \& Hasan (2017). The Influence of Transformational Leadership style,Organizational Culture and Work Dicipline on Employee Performance at PT. Pegadaian kantor cabang karombasan. Vol.5 No.3 September 2017, Hal.4555-4564. EMBA

Bass, B.M. (1998). Transformational Leadership: Industrial, Military, and Educational Impact. Mahwah, NJ. Erlbaum.

Bass, B. \& Avolio, B., (2011), "Full range leadership development: Manual for multifactor leadership questonaire", Redwood City, California: Mind Garden.

Boerner, Eisenbeiss, dan Griesser (2007) Follower Behavior and Organizational Performance: The Impact of Transformational Leaders. Journal of Leadership \& Organizational Studies. ; $13 ; 15$.

Elgelal dan Noermijati (2014). The Influences of Transformational Leaderships on Employees Performance. Asia Pacific Management and Business Application. 3(1):48-66. ResearchGate

Ghaffari, Nazri dan Burgoyne (2017). The Influence of Motivation on Job Performance: A Case Study at Universiti Teknologi Malaysia. Australian Journal of Basic and Applied Sciences.

Ghozali, Imam. 2006. Aplikasi Analisis Multivariate dengan Program SPSS. Semarang: Badan Penerbit Universitas Dipenogoro.

Ghozali, I., \& Latan, H. (2015). Partial Least Squares: Konsep, Teknik, dan Aplikasi Menggunakan Program SmartPLS 3.0. Semarang: Badan Penerbit Universitas Diponegoro.

Gibson I. (1988). Organisasi dan Manajemen Perilaku Struktur Proses (terjemahan Djoerban Wahid). Jakarta : Penerbit Erlangga

Jyoti dan Bhau (2015). Impact of Transformational Leadership on Job Performance: Mediating Role of Leader-Member Exchange and Relational Identification.SAGE

Laid, Mohammed \& Bindu (2020). Ethical leadership, emotional leadership, and quitting intentions in public organizations. Does employee motivation play a role?. Leadership \& Organization Development Journal, 41, 257-279. Emerald Publishing

Lee and Hidayat (2018). Advances in Management \& Applied Economics, vol. 8, no. 2, Scienpress Ltd

Mathis, Robert L dan John H. Jackson, (2012). Manajemen Sumber Daya Manusia. Buku 1, Alih Bahasa: Jimmy Sadeli dan Bayu. Prawira Hie, Salemba Empat. Jakarta

Rao \& Abdul (2015). Impact of transformational leadership on team performance: an empirical study in UAE. Measuring Bussiness Excelence.19, 30-56, Emerald Group Publishing Limited.

Robbins SP, dan Judge. (2008). Perilaku Organisasi. buku 2, Jakarta: salemba empat

Robbins, Stephen P., Timothy A. Judge. (2016). Perilaku Organisasi. Edisi 16. Jakarta : Salemba Empat.

Roy Johan, Wayan Gede, dan I Gede Riana (2014). "Pengaruh Kepemimpinan Transformasional Terhadap Motivasi Dan Kinerja Karyawan (Studi Kasus Pada PT. Pandawa)" E-Jurnal Ekonomi dan Bisnis Universitas Udayana. 3. 533-550.

Simanjuntak. (2005). Manajemen Dan Evaluasi Kinerja. Jakarta: Fakultas Ekonomi Universitas Indonesia

Sugiyono (2007). Metode Penelitian Kuantitatif dan Kualitatif. Bandung: Alfabeta. 
. (2013). Metode Penelitian Pendidikan Pendekatan Kuantitatif, Kualitatif. Bandung: Alfabeta.

. (2014). Metode Penelitian Pendidikan Pendekatan Kuantitatif, Kualitatif, dan R\&D. Bandung: Alfabeta.

Tichy, N. M., \& Devanna, M. A. (1986). The transformational leader. New York: Wiley. transformational leadership. Thousand Oaks, CA: Sage Publications

Yanuar (2017). Compensation, Motivation and Performance of Employees: Evidence from Indonesia. International Journal of Economic Perspectives. 11, 4, 486-492. International Economic Society

Yeti (2020). The Effect of Motivation on Employee Performance. Budapest International Research and Critics Institute-Journal (BIRCI-Journal). 3, 2, 995-1002

Yukl, Gary (2010). Kepemimpinan Dalam Organisasi, Edisi Kelima. Jakarta:PT. Indeks.

Zhang, Chen, Lyu dan Shu (2020). How does servant leadership influence employees service innovative behavior? The roles of intrinsic motivation and identification with the leader. Baltic Journal of Management. 15, 4, 571-586. Emerald Publishing Limited 